\title{
Milrinone attenuates the negative inotropic effects of landiolol in halothane-anesthetized dogs
}

\section{[La milrinone atténue les effets inotropes négatifs du landiolol chez des chiens}

\author{
anesthésiés avec de l'halothane]
}

Shinji Takahashi MD, Yoshitaka Fujii MD, Takuo Hoshi MD, Aki Uemura MD, Masayuki Miyabe MD, Hidenori Toyooka MD

\begin{abstract}
Background: Clinical use of high dose beta-blocker therapy is limited by excessive negative inotropic effects. Previous studies suggest that milrinone may be of utility in limiting the inotropic but not the chronotropic effects of beta blockers. We examined the hemodynamic effects of co-administration of a new potent selective beta blocker, landiolol, and milrinone in halothane-anesthetized dogs.
\end{abstract}

Methods: Eighteen adult mongrel dogs were anesthetized with I.2 MAC halothane. Hemodynamic measurements were made at baseline, $30 \mathrm{~min}$ after starting the milrinone $\left(0.5 \mu \mathrm{g} \cdot \mathrm{kg}^{-1} \cdot \mathrm{min}^{-1}\right)$ or normal saline infusion ( $n=9$ in each), then 30 min after each change in the dose of landiolol infusion. The tested doses of landiolol were 10, 100, and $1000 \mu \mathrm{g} \cdot \mathrm{kg}^{-1} \cdot \mathrm{min}^{-1}$.

Results: Landiolol ( $z=10 \mu \mathrm{g} \cdot \mathrm{kg}^{-1} \cdot \mathrm{min}^{-1}$ ) has significant and comparable negative chronotropic effects in both groups of dogs. While it also has significant negative inotropic effects in both groups, such effects are significantly attenuated in the dogs treated with milrinone.

Conclusion: Milrinone is effective to attenuate the negative inotropic effects of landiolol in halothane-anesthetized dogs.

Contexte : L'usage clinique de fortes doses thérapeutiques de B-bloquants est limité par des effets inotropes négatifs excessifs. Des études antérieures laissent voir que la milrinone peut limiter les effets inotropes, mais non chronotropes, des B-bloquants. Nous avons vérifié les effets hémodynamiques de la co-administration d'un nouveau B,bloquant, sélectif et puissant, le landiolol, et de milrinone chez des chiens anesthésiés avec de l'halothane.

Méthode : Dix huit chiens de race commune ont été anesthésiés avec 1,2 CAM d'halothane. Les tests hémodynamiques ont été faits au départ, 30 min après l'administration de milrinone $\left(0,5 \mu \mathrm{g} \cdot \mathrm{kg}^{-1} \cdot \mathrm{min}^{-1}\right)$ ou d'une perfusion de solution saline ( $n=9$ dans chaque groupe), puis 30 min après chaque changement de dose de landiolol. Les doses test de landiolol ont été de 10,100 et $1000 \mu \mathrm{g} \cdot \mathrm{kg}^{-1} \cdot \mathrm{min}^{-1}$.
Résultats : Le landiolol ( $\geq=10 \mu \mathrm{g} \cdot \mathrm{kg}^{-1} \cdot \mathrm{min}^{-1}$ ) a produit des effets chronotropes négatifs comparables et significatifs chez les deux groupes de chiens. II a aussi eu des effets inotropes négatifs significatifs chez les deux groupes, mais ces effets sont diminués de façon significative chez les chiens traités avec la milrinone.

Conclusion : La milrinone est efficace pour diminuer les effets inotropes négatifs du landiolol chez des chiens anesthésiés avec de l'halothane.

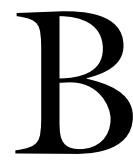

ETA-ADRENERGIC receptor blockers have been used widely in the treatment of tachycardia and dysrhythmias. ${ }^{1,2}$ Recent reports ${ }^{3-6}$ demonstrated that the prophylactic administration of beta-adrenergic blockers in patients with ischemic heart disease reduced the incidence of postoperative ischemic events and reduced mortality.

Landiolol, a new ultra-short acting, highly cardioselective beta-adrenergic receptor antagonist, is effective in the treatment of tachyarrhythmias in animals. ${ }^{7,8}$ While landiolol is more potent than esmolol ${ }^{7}$ in terms of chronotropy, it also has less effects on blood pressure than esmolol in anesthetized rabbits. ${ }^{9}$ Although there have been great advances in cardiac surgical techniques in the past decade, postoperative support with inotropic agents is still frequently necessary. ${ }^{10}$ Further, intraoperative prevention of hypotension and arrhythmias and maintenance of cardiac output $(\mathrm{CO})$ are critical in terms of patient outcome.

Milrinone is a well-known phosphodiesterase IIIinhibitor that has a potent positive inotropic effect and

From the Department of Anesthesiology, Institute of Clinical Medicine, University of Tsukuba, Tsukuba, Japan. Address correspondence to: Dr. Shinji Takahashi, Department of Anesthesiology, Institute of Clinical Medicine, University of Tsukuba,

Tenodai 1-1-1, Tsukuba-city 305-8575, Japan. Phone and FAX: 81-29-853-3092; E-mail: shinjitk@md.tsukuba.ac.jp Accepted for publication April 1, 2003.

Revision accepted July 4, 2003. 
is used to maintain $\mathrm{CO}$, both intraoperatively and postoperatively. ${ }^{11}$ However, the favourable effect of milrinone on $\mathrm{CO}$ may be negated by increases in heart rate (HR; and subsequent increases in myocardial oxygen consumption) that sometimes accompany its administration. ${ }^{12}$ The present study investigated the hemodynamic effects of the co-administration of landiolol and milrinone in halothane-anesthetized dogs. We hypothesized that milrinone would prevent the negative inotropic effects of landiolol but preserve the ability of landiolol to achieve optimal HR control.

\section{Methods}

This present study was approved by the Institutional Animal Care Committee. Eighteen adult mongrel dogs of either gender, weighing 12 to $16 \mathrm{~kg}(13.2 \pm 1.5 \mathrm{~kg}$ mean \pm SD), were included in the study. Animal preparation was similar to that described previously. ${ }^{8,13}$ Animals were anesthetized with $25 \mathrm{mg} \cdot \mathrm{kg}^{-1}$ pentobarbital $i v$, the trachea intubated with a cuffed tracheal tube, and the lungs ventilated mechanically. Anesthesia was maintained with $1.2 \mathrm{MAC}$ ( $1.0 \%$ end-tidal concentration) halothane in oxygen. An 18-gauge catheter was inserted into the femoral artery for continuous blood pressure monitoring and intermittent blood sampling. Another 18-gauge catheter was inserted into a femoral vein for drug and fluid administration. Drug infusions were delivered via motor driven syringe pumps (Termo Model STC-523®, Tokyo, Japan). A 7-Fr pulmonary artery catheter (Baxter Edwards Critical Care, Irvine, CA, USA) was inserted via a femoral vein and floated to the wedge position. Lead II of the electrocardiogram, arterial blood pressure (systolic, mean, and diastolic blood pressure), HR, mean pulmonary artery pressure (MPAP), pulmonary artery occlusion pressure (PAOP), and central venous pressure (CVP) were monitored continuously and recorded (Polygraph 7747 Amplifier Case ${ }^{\circledR}$, San-ei, Tokyo, Japan). CO was determined as the mean of three measurements determined by thermodilution using iced saline (Cardiac Output Computer 7350®, Arrow, Reading, PA, USA). Additional monitoring included arterial blood gas analysis, and electrolyte and hemoglobin concentration determination (Ciba Coring 288 Blood Gas System ${ }^{\circledR}$, Ciba Corning Diagnostics Corp. Medfield, MA, USA). Maintenance fluid (Ringer's lactate solution) was administered at a rate of $10 \mathrm{~mL} \cdot \mathrm{kg}^{-1} \cdot \mathrm{hr}^{-1}$. Metabolic acidosis (base excess $<-10.0$ ) was corrected with sodium bicarbonate as required. Serum potassium concentration was maintained between $3.5-4.5 \mathrm{mEq} \cdot \mathrm{L}^{-1}$ by infusing $\mathrm{KCl}$ as required. Arterial $\mathrm{pH}, \mathrm{PO}_{2}$, and serum sodium concentration were maintained within the range of 7.35 to $7.45,100$ to $200 \mathrm{mmHg}$, and 135 to
$145 \mathrm{mEq} \cdot \mathrm{L}^{-1}$, respectively. During the study, blood temperature was maintained between 36.5 to $38.5^{\circ} \mathrm{C}$ using an electric heating blanket. After at least $90 \mathrm{~min}$ of stabilization after initiating halothane-oxygen anesthesia, measurements of all hemodynamic variables were performed to define baseline values. Systemic vascular resistance (SVR) and pulmonary vascular resistance (PVR) were derived according to the following equation: $\mathrm{SVR}=\{($ mean blood pressure $; \mathrm{MBP}-\mathrm{CVP}) \mathrm{x}$ $80\} / \mathrm{CO}$, and PVR $=\{($ MPAP-PAOP $) \times 80\} / \mathrm{CO}$. After measurements of baseline hemodynamic variables, dogs were randomly assigned according to computer-generated random numbers into one of two groups ( $n=9$ in each): 1) a milrinone group, or 2) a control (normal saline) group.

The dogs in the control group received $i v$ normal saline $(10 \mathrm{~mL}$ bolus injection over five minutes, followed by a continuous infusion of $5 \mathrm{~mL} \cdot \mathrm{hr}^{-1}$ ). The dogs in the milrinone group received milrinone as an $i v$ infusion $\left(50 \mu \mathrm{g} \cdot \mathrm{kg}^{-1}\right.$ body weight in $5 \mathrm{~mL}$ over five minutes, followed by a continuous infusion of 0.5 $\mu \mathrm{g} \cdot \mathrm{kg}^{-1} \cdot \mathrm{min}^{-1}$ milrinone). The investigators who injected the drug and observed the hemodynamic changes were blinded to the treatment group of the dogs. Thirty minutes after milrinone or saline infusion, hemodynamic variables were measured. After measurements of hemodynamic baseline variables (landiolol $0 \mu \mathrm{g} \cdot \mathrm{kg}^{-1} \cdot \mathrm{min}^{-1}$ ), $10 \mu \mathrm{g} \cdot \mathrm{kg}^{-1} \cdot \mathrm{min}^{-1}$ of landiolol was administered for $30 \mathrm{~min}$ in each group. Hemodynamic variables were measured before and at 15 and $30 \mathrm{~min}$ after landiolol administration. At least $30 \mathrm{~min}$ after cessation of landiolol, hemodynamic measurements were repeated using the same protocol with an increasing concentration of landiolol (100 then $1000 \mu \mathrm{g} \cdot \mathrm{kg}^{-1} \cdot \mathrm{min}^{-1}$ ) in the same dogs.

The data are expressed as mean \pm SD. Statistical analysis was performed using a commercially available software package (StatView ${ }^{\circledR}$, Ver.5.0, Abacus Concepts, Inc., Berkeley, CA, USA). Hemodynamic variables between the groups were analyzed using analysis of variance (ANOVA) with Bonferroni's correction. Data from each group were analyzed using paired t test. $P$ value of $<0.05$ was considered significant.

\section{Results}

Hemodynamic changes after saline or milrinone infusions are summarized in Table I. There were no significant differences between groups in the pre-treatment values. Thirty minutes after administration of milrinone, measurements revealed increases in $\mathrm{HR}$ and CO, and decreases in CVP, MPAP, PAOP and SVR when compared to pre-treatment values. Systolic blood pressure (SBP), MBP and diastolic blood pres- 
TABLE I Hemodynamic changes after saline/milrinone treatment

\begin{tabular}{|c|c|c|c|c|}
\hline & \multicolumn{2}{|c|}{ Saline } & \multicolumn{2}{|c|}{ Milrinone } \\
\hline & Before ${ }^{a}$ & After ${ }^{b}$ & Before ${ }^{a}$ & After ${ }^{b}$ \\
\hline SBP (mmHg) & $144 \pm 28$ & $142 \pm 28$ & $141 \pm 29$ & $140 \pm 30$ \\
\hline $\mathrm{MBP}(\mathrm{mmHg})$ & $117 \pm 20$ & $116 \pm 20$ & $116 \pm 21$ & $113 \pm 22$ \\
\hline $\mathrm{DBP}(\mathrm{mmHg})$ & $98 \pm 17$ & $97 \pm 16$ & $99 \pm 19$ & $96 \pm 19$ \\
\hline HR (beats. min $^{-1}$ ) & $119 \pm 31$ & $120 \pm 33$ & $111 \pm 28$ & $116 \pm 29^{*}$ \\
\hline $\mathrm{CVP}(\mathrm{mmHg})$ & $2.4 \pm 1.0$ & $2.2 \pm 1.2$ & $3.2 \pm 1.9$ & $2.0 \pm 1.4^{*}$ \\
\hline MPAP $(\mathrm{mmHg})$ & $17.6 \pm 6.5$ & $16.4 \pm 7.1$ & $18.7 \pm 7.0$ & $15.9 \pm 6.0^{*}$ \\
\hline PAOP (mmHg) & $10.0 \pm 6.0$ & $10.2 \pm 6.5$ & $12.7 \pm 5.7$ & $9.6 \pm 6.4^{*}$ \\
\hline $\mathrm{CO}\left(\mathrm{L} \cdot \mathrm{min}^{-1}\right)$ & $1.65 \pm 0.54$ & $1.64 \pm 0.48$ & $1.35 \pm 0.29$ & $1.95 \pm 0.43^{*}$ \\
\hline $\operatorname{SVR}\left(\right.$ dyne $\left.\cdot \mathrm{sec}^{-1} \cdot \mathrm{cm}^{-5}\right)$ & $5921 \pm 1603$ & $5875 \pm 1445$ & $6836 \pm 1285$ & $4681 \pm 1005^{*}$ \\
\hline PVR (dyne $\cdot \mathrm{sec}^{-1} \cdot \mathrm{cm}^{-5}$ ) & $401 \pm 131$ & $337 \pm 180$ & $427 \pm 241$ & $324 \pm 161$ \\
\hline
\end{tabular}

Each value is mean \pm SD. $\mathrm{a}=$ obtained just before treatment; $\mathrm{b}=$ obtained 30 min after saline or milrinone treatment; SBP $=$ systolic blood pressure; $\mathrm{MBP}=$ mean blood pressure; $\mathrm{DBP}=$ diastolic blood pressure $\mathrm{HR}=$ heart rate $\mathrm{CVP}=$ central venous pressure $\mathrm{MPAP}=$ mean pulmonary artery pressure; $\mathrm{PAOP}=$ pulmonary artery occlusion pressure $; \mathrm{CO}=$ cardiac output; $\mathrm{SVR}=$ systemic vascular resistance; $\mathrm{PVR}=$ pulmonary vascular resistance. ${ }^{*} P<0.05$ vs before values.

sure (DBP) values showed no change. Hemodynamic variables did not change significantly after saline infusion in the control group.

Hemodynamic changes after administration of landiolol are shown in the Figure. Significant decreases in $\mathrm{HR}$ and $\mathrm{CO}$ were observed in both groups after administration of $\geq=10 \mu \mathrm{g} \cdot \mathrm{kg}^{-1} \cdot \mathrm{min}^{-1}$ landiolol, and there was no significant difference in HR, SBP, DBP, MBP, CVP, PAP, PAOP, or PVR between the two groups after landiolol administration (Table II, available as additional material at www.cja-jca.org). The administration of $0.5 \mu \mathrm{g} \cdot \mathrm{kg}^{-1} \cdot \mathrm{min}^{-1}$ milrinone attenuated the decrease in $\mathrm{CO}$ seen with the administration of landiolol (Figure), while SVR decreased with the administration of milrinone $\left(100 \mu \mathrm{g} \cdot \mathrm{kg}^{-1} \cdot \mathrm{min}^{-1}\right.$ or more). There were no unexpected deaths in either group of animals, and dysrhythmia did not occur.

\section{Discussion}

The present study demonstrated that chronotropic control was achieved with a landiolol dose of 10 $\mu \mathrm{g} \cdot \mathrm{kg}^{-1} \cdot \mathrm{min}^{-1}$. These results are consistent with our previous report ${ }^{13}$ that a $10 \mu \mathrm{g} \cdot \mathrm{kg}^{-1} \cdot \mathrm{min}^{-1}$ dose of landiolol suppressed tachycardia-induced theophylline intoxication. In another report, ${ }^{14}$ Sugiyama et al. demonstrated that the isoproterenol-induced increase in HR was halved by $1.5 \pm 0.9 \mu \mathrm{g} \cdot \mathrm{kg}^{-1} \cdot \mathrm{min}^{-1}$ of landiolol or by $9.3 \mu \mathrm{g} \cdot \mathrm{kg}^{-1} \cdot \mathrm{min}^{-1}$ of esmolol in halothaneanesthetized dogs. Thus, landiolol was six times more potent than esmolol in attenuating increases in $\mathrm{HR}$. The present study also demonstrated that milrinone $\left(0.5 \mu \mathrm{g} \cdot \mathrm{kg}^{-1} \cdot \mathrm{min}^{-1}\right)$ did not alter the ability of landiolol to control HR.
Sasao et al. ${ }^{9}$ demonstrated that $300 \mu \mathrm{g} \cdot \mathrm{kg}^{-1} \cdot \mathrm{min}^{-1}$ esmolol produced hypotension in rabbits, while 300 $\mu \mathrm{g} \cdot \mathrm{kg}^{-1} \cdot \mathrm{min}^{-1}$ landiolol had no effect on blood pressure. In our study, $1000 \mu \mathrm{g} \cdot \mathrm{kg}^{-1} \cdot \mathrm{min}^{-1}$ landiolol produced a $20 \%$ decrease in SBP from baseline value. Although milrinone has a potent vasodilating effect that occasionally induced hypotension, the change in blood pressure with landiolol was not altered by the co-administration of $0.5 \mu \mathrm{g} \cdot \mathrm{kg}^{-1} \cdot \mathrm{min}^{-1}$ milrinone.

Milrinone administration resulted in a $44 \%$ increase in $\mathrm{CO}$, while landiolol produced a dose-dependent decrease in CO. However, when landiolol was administered in animals that also received milrinone, $\mathrm{CO}$ was maintained.

Propranolol is a non-selective beta-adrenergic receptor antagonist $\left(\right.$ beta $_{1} /$ beta $_{2}$-receptor activity $\left(\beta_{1} / \beta_{2}\right)=$ $33)^{7}$ that results in increased SVR secondary to its beta $_{2}$-blocking effects. ${ }^{15}$ In contrast, landiolol is a highly selective beta ${ }_{1}$-adrenergic receptor antagonist $\left(\beta_{1} / \beta_{2}\right.$ $=255)^{7}$ that had a minimal effect on SVR in pentobarbital-anesthetized dogs, even with high-dose administration. ${ }^{15}$ The present study observed an increase in SVR in the saline-treated animals with landiolol 100 $\mu \mathrm{g} \cdot \mathrm{kg}^{-1} \cdot \mathrm{min}^{-1}$ but showed no change with landiolol administration in the milrinone-treatment group.

Carceles et al. ${ }^{16}$ demonstrated that GI104313, a chimeric molecule containing a combined phosphodiesterase-inhibiting pyradazinone and a blocking phenoxypropanolamine, induced a decrease in arrhythmia and mortality that was not associated with changes in ventricular cyclic nucleotide content in rats. Recent knock-out mouse studies suggested that specific beta ${ }_{1}^{-}$ adrenergic receptor blockade, and not beta ${ }_{2}$ blockade, 


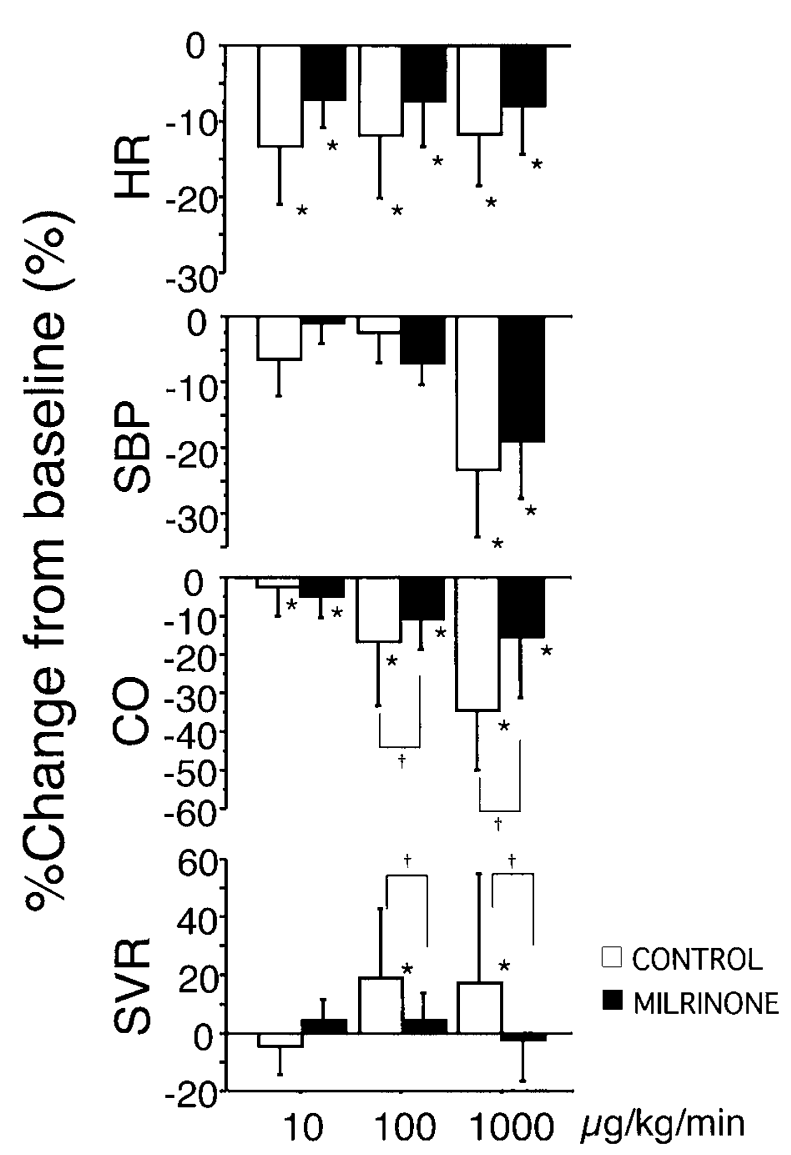

FIGURE Percent changes in heart rate (HR), systolic blood pressure (SBP), cardiac output $(\mathrm{CO})$, and systemic vascular resistance (SVR) from baseline values after $i v$ injection of landiolol. Values are mean \pm SD. ${ }^{*} P<0.05$ vs baseline value. $\dagger P<0.05$ vs the control group.

was responsible for cardioprotection and prevention of myocyte apoptosis. ${ }^{17}$ Further investigation is necessary to prove the efficacy of combined phosphodiesterase inhibition and beta blockade in ischemic hearts.

There are several notable limitations in this study. First, these studies were conducted on dogs with normal hearts and without cardiac insufficiency. The hemodynamic effects of landiolol and milrinone may differ in patients with severe cardiac disease and low CO. Second, we did not perform experiments with higher doses of milrinone. Increasing doses of milrinone may reverse the decrease in CO produced by landiolol. However, milrinone has a vasodilating effect and could also potentiate hypotension induced by landiolol. Third, this study was of short duration and did not address the long-term effects of treatment with these agents.
In conclusion, milrinone is effective to attenuate the negative inotropic effects of landiolol in halothane-anesthetized dogs.

\section{Acknowledgement}

The authors would like to acknowledge Ono Pharmaceutical Co., Ltd. Osaka, Japan, for supplying landiolol (ONO-1101).

\section{References}

1 Gold MI, Sacks DJ, Grosnoff DB, Herrington C, Skillman CA. Use of esmolol during anesthesia to treat tachycardia and hypertension. Anesth Analg 1989; 68: 101-4.

2 Vucevic M, Purdy GM, Ellis FR. Esmolol hydrochloride for management of the cardiovascular stress responses to laryngoscopy and tracheal intubation. Br J Anaesth 1992; 68: 529-30.

3 Urban MK, Markowitz SM, Gordon MA, Urqubart BL, Kligfield $P$. Postoperative prophylactic administration of $B$-adrenergic blockers in patients at risk for myocardial ischemia. Anesth Analg 2000; 90: 1257-61.

4 Raby KE, Brull SJ, Timimi F, et al. The effect of heart rate control on myocardial ischemia among high-risk patients after vascular surgery. Anesth Analg 1999; 88: 477-82.

5 Poldermans D, Boersma E, Bax JJ, et al. The effect of bisoprolol on perioperative mortality and myocardial infarction in high-risk patients undergoing vascular surgery. N Engl J Med 1999; 341: 1789-94.

6 Mangano DT, Layug EL, Wallace A, Tateo I. Effect of atenolol on mortality and cardiovascular morbidity after noncardiac surgery. N Engl J Med 1996; 335: 1713-20.

7 Iguchi S, Iwamura H, Nishizaki M, et al. Development of a highly cardioselective ultra short-acting B-blocker, ONO-1101. Chem Pharm Bull 1992; 40: 1462-9.

8 Takabashi S, Fujii $\Upsilon$, Inomata S, Miyabe M, Toyooka $H$. Landiolol increases a dysrhythmogenic dose of epinephrine in dogs during halothane anesthesia. Can J Anesth 1999; 46: 599-604.

9 Sasao J, Tarver SD, Kindscher JD, Taneyama C, Benton $K T$, Goto $H$. In rabbit, landiolol, a new ultra-short-acting B-blocker, exerts a more potent negative chronotropic effect and less effect on blood pressure than esmolol. Can J Anesth 2001; 48: 985-9.

10 Heames RM, Gill RS, Ohri SK, Hett DA. Off-pump coronary artery surgery. Anaesthesia 2002; 57: 676-85.

11 Butterworth JF, Hines RL, Royster RL, James RL. A pharmacokinetic and pharmacodynamic evaluation of milrinone in adults undergoing cardiac surgery. Anesth Analg 1995; 81: 783-92. 
12 Skoyles JR, Sherry KM. Pharmacology, mechanisms of action and uses of selective phosphodiesterase inhibitors. Br J Anaesth 1992; 68: 293-302.

13 Takabashi S, Fujii $\Upsilon$, Hoshi T, Inomata S, Miyabe M, Toyooka $H$. Modifications of the hemodynamic consequences of theophylline intoxication with landiolol in halothane-anesthetized dogs. Can J Anesth 2000; 47: 265-72.

14 Sugiyama A, Takahara A, Hashimoto $K$.

Electrophysiologic, cardiohemodynamic and B-blocking actions of a new ultra-short-acting ß-blocker, ONO-1101, assessed by the in vivo canine model in comparison with esmolol. J Cardiovasc Pharmacol 1999; 34: 70-7.

15 Shiroya T, Matsumori $\Upsilon$, Sawada $S$, et al. Effect of ONO-1101, an ultra-short acting ß1-blocker, on cardiohemodynamics in anesthetized dogs (Japanese). Clin Res 1997; 31: 2949-65.

16 Carceles MD, Aleixandre F, Fuente T, Lopez-Vidal J, Laorden ML. Combined phosphodiesterase inhibition and B-blockade in the GI104313, decreases ischemiainduced arrhythmias in the rat. Can J Anesth 2001; 48: 486-92.

17 Zaugg M, Schaub MC, Pasch T, Spahn DR. Modulation of $ß$-adrenergic receptor subtype activities in perioperative medicine: mechanisms and sites of action. $\mathrm{Br} \mathrm{J}$ Anaesth 2002; 88: 101-23.

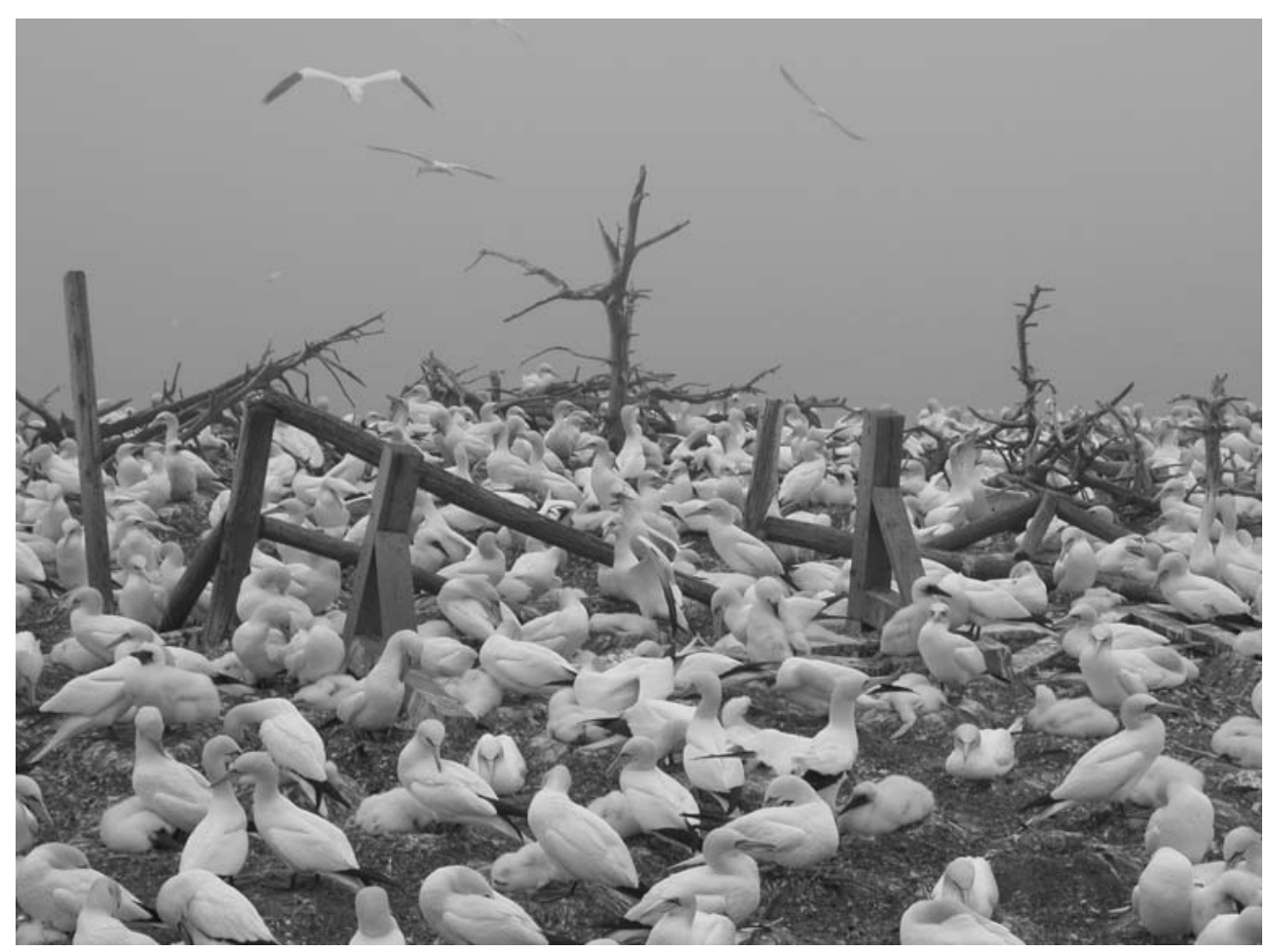

Ile Bonaventure - Québec 